\title{
TWO TYPES OF LOCATIVE INVERSION CONSTRUCTION IN ENGLISH
}

\author{
KOJI KOIKE \\ Nagoya University
}

\begin{abstract}
This paper provides a syntactic analysis of the locative inversion construction in English, dividing it into two types: one with an unaccusative verb and the other with an unergative verb. It is argued that the former type has the locative PP simultaneously attracted by $\mathrm{T}$ and Top by applying the idea of "independent probing" proposed by Chomsky (2008). On the other hand, the latter type has a syntactic structure in which the subject DP undergoes Heavy NP Shift, while the locative PP moves only to SpecTopP, but not to SpecTP. It is shown that the analysis based on these syntactic structures can give a principled explanation to the major syntactic properties of the two types of locative inversion construction within the framework of the Minimalist Program.*
\end{abstract}

Keywords: locative inversion construction, phase, independent probing, Heavy NP Shift

\section{Introduction}

There have been many studies on locative inversion with an unaccusative verb as exemplified in (1). They have focused on the syntactic and semantic properties of the postverbal subject DP and the sentence-initial locative PP, and there is some consensus that the latter has dual status as a subject and as a topic (Bresnan (1994), Nishihara (1999), Kitada (2011) among others).

(1) a. On the stage appeared a man.

(Coopmans (1989: 743))

b. Onto the ground had fallen a few leaves.

c. Down the hill rolled Mary.

(Bresnan (1994: 78))

(Doggett (2004: 22))

* First of all, I would like to express my deep gratitude to my teachers, Takeshi Omuro and Tomoyuki Tanaka. Then, I am also grateful to my seniors and colleagues. Needless to say, all remaining errors are my own.

English Linguistics 30: 2 (2013) 568-587 - 568(C) 2013 by the English Linguistic Society of Japan 
On the other hand, there have been only a few studies on locative inversion with an unergative verb as shown in (2). Among them, Culicover and Levine (2001) argue that the postverbal subject DP must be heavy in the sense of Heavy NP Shift (henceforth, HNPS), and that the sentence-initial locative PP shows only topichood, but not subjecthood.

(2) a. On the third floor worked two young women called Maryanne Thomson and Ava Brent, who ran the radio library and print room.

(Levin and Rappaport Hovav (1995: 225))

b. In the room slept fitfully the students in the class who had heard about the social psych experiment that we were about to perpetrate.

(Culicover and Levine (2001: 293))

c. Around the fire chattered and sang many girls and boys wearing their native costumes.

(Kuno and Takami (2007: 275))

Thus, there are two types of locative inversion construction (henceforth, LIC): the LIC with an unaccusative verb and the LIC with an unergative verb, which I will call the unaccusative LIC and the unergative LIC, respectively. This paper aims to clarify the syntactic structures of the two types of LIC and give a principled explanation to their syntactic properties within the framework of the Minimalist Program.

The organization of this paper is as follows. Section 2 discusses the unaccusative LIC, and argues that the locative PP moves to SpecTP and SpecTopP simultaneously by applying the idea of independent probing as described in Chomsky (2008). Section 3 elaborates on the unergative LIC along the lines of Culicover and Levine (2001), and proposes its syntactic structure in which the subject DP undergoes HNPS and the locative PP moves only to SpecTopP. Section 4 overviews Mikami (2010) and Kitada (2011) among previous studies on the LIC, pointing out their empirical insufficiencies. Section 5 offers concluding remarks.

\section{The Unaccusative LIC}

\subsection{Theoretical Background}

It has been standardly assumed within the framework of the Minimalist Program that the derivation of a sentence proceeds in a bottom-up cyclic way, so that an operation by a head applies before an operation by the higher head that is merged later. Chomsky (2008) partly modifies this assumption under the phase-based derivational model, in which operations by separate heads within the same phase apply in parallel. This is illustrated 
by the movement that who undergoes in (3).

(3) a. Who saw John?

(Chomsky (2008: 149))

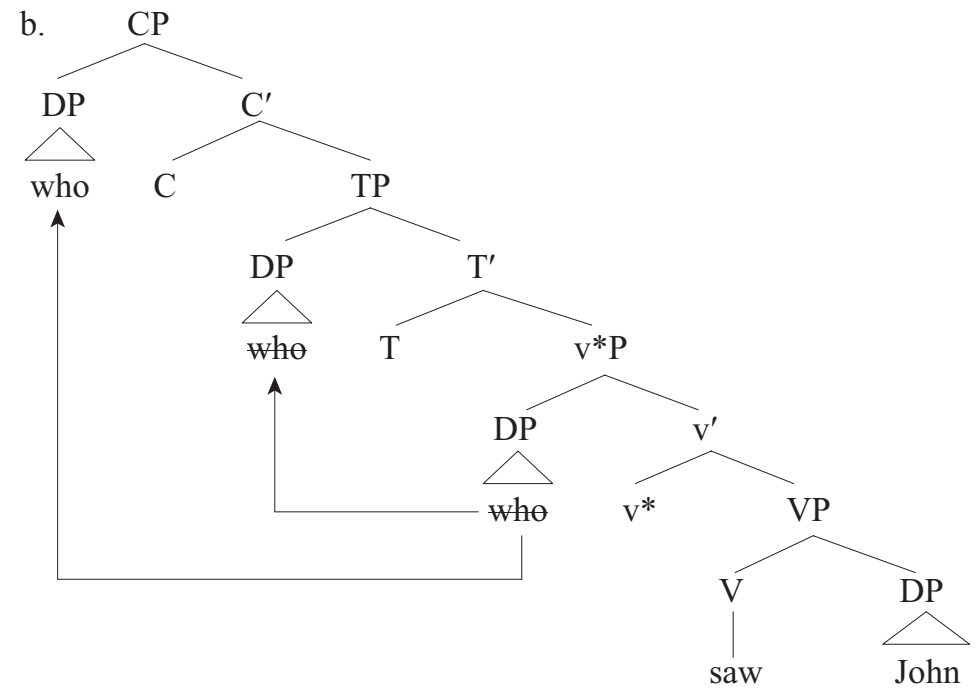

In the $\mathrm{CP}$ phase, the Agree feature on $\mathrm{T}$ probes and enters into an Agree relation with who in Specv*P, and the EPP-feature on $\mathrm{T}$ probes and attracts it from Specv*P to SpecTP. At the same time, the edge feature on $\mathrm{C}$ probes and attracts who from Specv*P to SpecCP. The two operations by $\mathrm{T}$ and $\mathrm{C}, \mathrm{A}-$-movement and $\mathrm{A}^{\prime}$-movement, respectively, apply in parallel and independently of each other. Then, based on the copy theory of movement (cf. Chomsky (1995)), only the highest copy of who in SpecCP is overtly spelled out and the other copies are deleted in the phonological component. This sort of derivation is called "independent probing" in this paper (cf. Radford (2009)).

2.2. The Syntactic Structure of the Unaccusative LIC

This paper proposes the following syntactic structure of the unaccusative LIC. ${ }^{1}$

${ }^{1}$ In what follows, the operations and categories irrelevant for the present discussion are omitted: for example, V-to-v movement (Chomsky (1995)) and FinP/ForceP in the Split-CP hypothesis (Rizzi (1997)). 
(4) a. To the platform came a train.

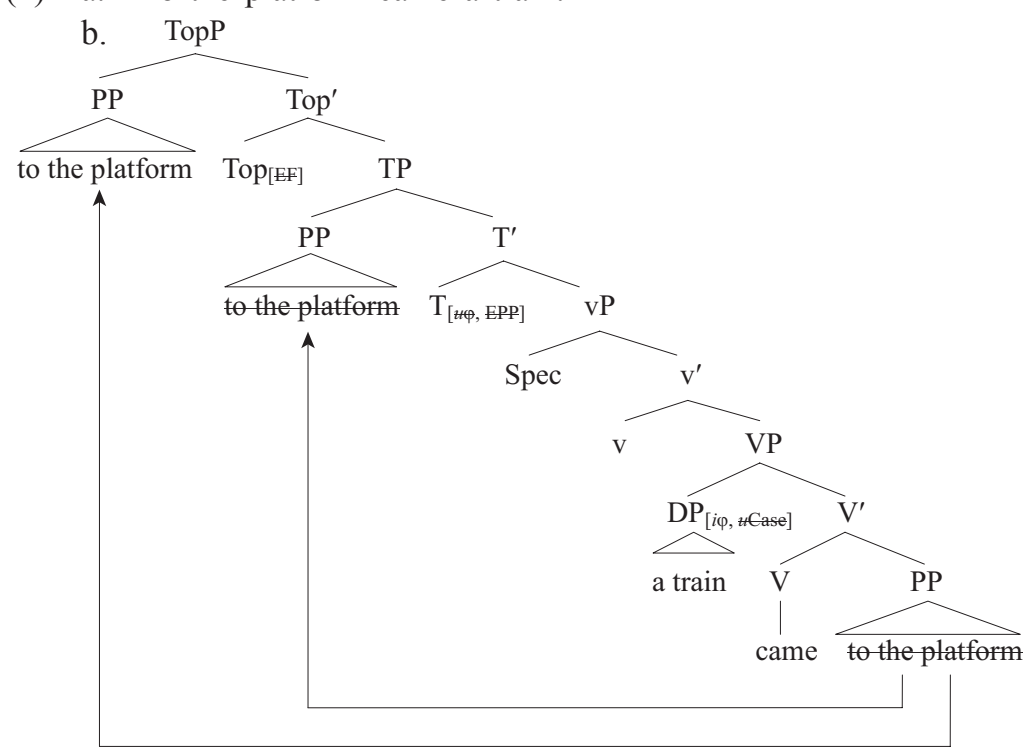

In (4), the subject DP is merged in SpecVP, and the locative PP is merged in the complement position of $\mathrm{V}$, respectively. According to the idea of independent probing, the operations by $\mathrm{T}$ and Top apply in parallel and independently of each other. The Agree feature on $\mathrm{T}$ probes and enters into an Agree relation with the subject DP in SpecVP, deleting the Agree feature on $\mathrm{T}$ and the Case feature on the subject DP which are both uninterpretable. In addition, the EPP-feature on $\mathrm{T}$ probes and attracts the locative PP from the complement position of $\mathrm{V}$ to SpecTP. ${ }^{2}$ In parallel with this A-movement triggered by $\mathrm{T}$, the edge feature on Top probes and attracts the locative PP from the complement position of $\mathrm{V}$ to SpecTopP. Since all the uninterpretable features have now been deleted, the derivation con-

2 This paper assumes that the locative PP can move across the subject DP to satisfy the EPP-feature on T in the unaccusative LIC. See Collins (1997) for an analysis of this locality problem in terms of the notion of equidistance: both the subject DP and the locative PP are in the same minimal domain of $\mathrm{V}$ and hence can be equally accessed from T. Another possible solution would be that EPP-checking does not depend on Agree and hence is not subject to intervention effects; see Chomsky (2008) for the suggestion that the EPP-feature is an edge feature inherited from $\mathrm{C}$ which can be checked without Agree. Incidentally, if the EPP-feature on T probes and attracts the subject DP to SpecTP, the derivation will also converge, yielding the non-inverted order as in (i).

(i) To the platform a train came. 
verges. Then, only the highest copy of the locative PP is overtly spelled out and the other copies are deleted in the phonological component, yielding the surface form of (4a). ${ }^{3,4}$

It is important to note that the present analysis of the unaccusative LIC does not assume successive cyclic movement of the locative PP from the complement position of $\mathrm{V}$ to SpecTP and then to SpecTopP. This is what Nishihara (1999) proposes, but his analysis is problematic because local subject topicalization is generally impossible (cf. Lasnik and Saito (1992)); see also Mikami (2010) for other problems with Nishihara's analysis). Instead, this section has proposed the syntactic structure of the unaccusative LIC in which the locative PP moves to SpecTP and SpecTopP simultaneously under independent probing by $\mathrm{T}$ and Top. ${ }^{5}$

3 The hierarchical order between the subject DP and the locative PP in (4) is based on Hale and Keyser's (1993) analysis (see also Larson (1988), Chomsky (1995), and Collins (1997)). However, if the reverse order, in which the locative PP and the subject DP are merged in SpecVP and the complement position of $\mathrm{V}$, respectively, were to be correct (see Mikami's (2010) analysis in (19) below), the derivation based on independent probing by $\mathrm{T}$ and Top would converge: the Agree feature on $\mathrm{T}$ could probe and enter into an Agree relation with the subject DP across the locative PP because the latter does not have matching $\varphi$-features to induce intervention effects. Of course, the movement of the locative PP to SpecTP and SpecTopP would pose no problems.

4 One might wonder whether the movement of the locative PP to SpecTop is necessary at all, because the word order of the unaccusative LIC could be derived without it. Under the recent Minimalist framework adopted here (Chomsky (2008)), A'-movement is triggered by an edge feature without Agree, and the interpretive effect associated with it is determined by its final landing site; the locative PP must move to SpecTopP to be interpreted as a topic. Alternatively, on the assumption that $\mathrm{A}^{\prime}$-movement is contingent on Agree (Chomsky (2000)), it might be suggested that Top has an uninterpretable topic feature that enters into an Agree relation with the locative PP, and the edge feature on Top probes and attracts it to SpecTopP. Apart from these conceptual arguments, there is also empirical evidence for postulating the movement of the locative PP to SpecTopP, as we will see in the next section.

Incidentally, the status of the postverbal subject DP as a focus follows as a consequence of the present analysis. Since the locative PP moves to SpecTP to satisfy the EPP-feature on T, the subject DP remains in its base position within VP in the course of the derivation. Assuming with Partee (1991) and Diesing (1992) that focused elements are mapped onto the nuclear scope of a sentence, which is $\mathrm{vP} / \mathrm{VP}$ in syntactic representation, the postverbal subject DP will be assigned a focus interpretation.

${ }^{5}$ In the framework of the Minimalist Program, there are two potential derivations of local subject topicalization, both of which must be excluded because they are impossible, as noted in the text. First, the derivation in which a subject DP undergoes successive cyclic movement to SpecTP and then to SpecTopP is impossible, if Chomsky (2008) is correct in assuming that an A-chain becomes invisible to further computation when its Case feature is valued; a subject DP is frozen in SpecTP. Second, one might ask wheth- 
The next section shows how the proposed analysis accounts for the major syntactic properties of the unaccusative LIC.

\subsection{Explaining the Properties of the Unaccusative LIC}

First, let us consider the properties of the postverbal subject DP. As shown in (5), it is not the sentence-initial locative PP, but the postverbal subject DP that agrees with the verb. This is straightforward under the present analysis because it agrees with $\mathrm{T}$ in situ, and hence be must be properly inflected as were in (5).

(5) In the swamp were/*was found two children.

(Bresnan (1994: 95))

Moreover, it is observed from the following contrast that the postverbal subject DP cannot control PRO in adjunct clauses, while the preverbal subject DP occupying SpecTP can. This paper assumes that adjunct clauses with PRO controlled by matrix subjects are adjoined to vP (cf. Nissenbaum (2000), Hornstein and Nunes (2002)).

(6) a. *Near the oasis lay [two sheiks] $]_{\mathrm{i}}$ without $\mathrm{PRO}_{\mathrm{i}}$ talking.

b. *... [vр $\left[{ }_{\mathrm{vp}}\left[\mathrm{vp}\right.\right.$ two sheiks $\left.\left.\mathrm{s}_{\mathrm{i}} \ldots\right]\right]$ without $\mathrm{PRO}_{\mathrm{i}}$ talking]

(7) [Two sheiks $]_{i}$ lay near the oasis without $\mathrm{PRO}_{\mathrm{i}}$ talking.

(Nishihara (1999: 393))

Given that obligatorily controlled PRO must be c-commanded by its antecedent in an A-position (cf. Williams (1980), Safir (2004)), the ungrammaticality of (6a) follows because the subject DP, which remains in VP, cannot c-command PRO in the adjunct clause in the proposed structure of the unaccusative LIC, as shown in (6b). ${ }^{6}$

er a subject DP can move to SpecTP and SpecTopP simultaneously under independent probing by $\mathrm{T}$ and Top. However, it is generally assumed that a subject DP in preverbal position, namely in SpecTP, is an unmarked topic of a sentence: it denotes an entity which the rest of the sentence is predicated of (cf. Lambrecht (1994)). Therefore, it is apparently redundant for it to move to SpecTopP in addition to SpecTP. In this case, assignment of edge feature to Top will be blocked on the assumption that a phase head is assigned an edge feature only if it has an effect on outcome (cf. Chomsky (2001)). On the other hand, a locative PP, which is not an unmarked topic of a sentence, must move to SpecTopP to be interpreted as a topic, so that it can move to SpecTP and SpecTopP simultaneously under independent probing by $\mathrm{T}$ and Top, as shown in the derivation of the unaccusative LIC in (4).

${ }^{6}$ In the unaccusative LIC, the subject DP can control PRO in adjunct clauses if it undergoes HNPS, as shown in (ia), with its structure in (ib). 
Next, consider the properties of the sentence-initial locative PP. As mentioned above, it has been observed in the literature that it has dual properties as a subject and as a topic. One piece of evidence for its subjecthood is that it may undergo raising when the unaccusative LIC is embedded under raising predicates, as shown in $(8 \mathrm{a})$, with its structure in $(8 \mathrm{~b})$ under the present analysis.

(8) a. [On that hill] appears to be located a cathedral.

(Doggett (2004: 29))

b. [торР PP [тP PP [vP appears [те PP to [vР be located ... PP]]]]]

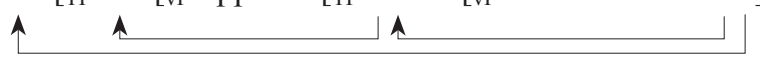

(PP: on that hill)

In (8b), the EPP-feature on the lower $\mathrm{T}$ attracts the locative PP to the embedded SpecTP, while the edge feature on Top attracts it to SpecTopP, under independent probing by the two heads. Then, the EPP-feature on the higher $\mathrm{T}$ attracts it from the embedded SpecTP to the matrix SpecTP. After these operations, its highest copy is spelled out, yielding the surface form of (8a). This fact lends support to the present analysis of the unaccusative LIC: the A-movement of the locative PP triggered by the local T feeds another instance of A-movement, i.e. raising, without causing improper move-

(i) a. Near the oasis lay, without PRO talking, two sheiks.

(Coopmans (1989: 732))

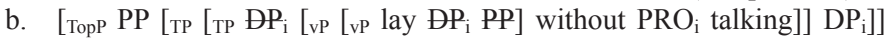

(PP: near the oasis, DP: two sheiks)

In (ib), the subject DP moves to SpecTP and then undergoes HNPS to adjoin to TP, while the locative PP moves only to SpecTopP. This derivation converges with all the uninterpretable features deleted, and yields the word order in which the subject DP follows the adjunct clause. Here, PRO in the adjunct clause can be properly c-commanded by the copy of the subject DP in SpecTP, thereby accounting for the grammaticality of (ia). As we will see in section 3, the same sort of derivation with HNPS is what underlies the unergative LIC. If this discussion is correct, the unaccusative LIC with a heavy subject DP will have two possible derivations: one with HNPS as in (i) and the other based on independent probing as in (4). The possibility of the latter is supported by the fact in (ii) that the unaccusative LIC with a heavy subject DP can be embedded under raising predicates, which indicates that the locative PP moves to SpecTP (as well as SpecTopP) and hence the subject DP stays in its base position. See the discussion on (8) below.

(ii) In these villages are likely to be found the best examples of this cuisine.

(Bresnan (1994: 96)) 
ment. ${ }^{7,8}$

Turning now to the topichood of the sentence-initial locative PP, it is worth noting that it blocks $\mathrm{A}^{\prime}$-movement of the subject DP, exhibiting the so-called "topic island effect," as shown in (9a), with its structure in (9b) under the present analysis.

(9) a.?*What kind of mushroom do you think [on these trails can be found___ ? (Bresnan (1994: 87))

b.?* ... think [ForceP $\mathrm{DP}\left[\right.$ TорР on these trails $\left[{ }_{\mathrm{TP}} \ldots\right.$ be found DP ... $\left.\left.]\right]\right]$ ?

(DP: what kind of mushroom)

This paper follows Maeda (2012) in assuming that TopP (as well as ForceP) is a phase in the $\mathrm{CP}$ domain, based on its similarity to $\mathrm{v} * \mathrm{P}$ in that topicalization forms a predication consisting of a topic and a comment on it. Given this, once the derivation reaches the TopP phase, the domain of Top, i.e. TP, is transferred to the phonological and semantic components and hence becomes inaccessible to operations outside TopP, in accordance with the Phase Impenetrability Condition (henceforth, PIC) proposed by Chomsky $(2000,2001)$. Therefore, the edge feature on Force cannot probe and attract the subject DP across the locative PP in SpecTopP without violating the PIC, as shown in (9).

7 It should be noted that the two heads independently probing the locative PP are (the matrix) Top and the lower $\mathrm{T}$ in (8b), since infinitival complements to raising predicates are TP lacking Top. The subsequent movement of the locative PP from the embedded SpecTP to the matrix SpecTP instantiates raising triggered by the higher T, and hence is not part of the derivation of locative inversion based on independent probing.

${ }^{8}$ The absence of weak crossover effects can also be explained under the present analysis.

(i) a. In every $\operatorname{dog}_{\mathrm{i}}$ 's cage hung its $\mathrm{s}_{\mathrm{i}}$ collar. (Culicover and Levine (2001: 290))

b. [TорР PP [TP PP [vp hung its collar PP]]

(PP: in every dog's cage)

In (i), the locative PP can move across the coreferential pronoun contained within the subject DP. Given the assumption that a bound variable pronoun must be A-bound by its antecedent (cf. Reinhart (1983)), this sentence is grammatical because the locative PP undergoes A-movement to SpecTP to function as an appropriate antecedent of the bound variable pronoun. Note that every dog does not c-command its in (i) under the standard definition of c-command. But this problem can be overcome by adopting the following condition in Hornstein (1995): its can be linked to every dog (more precisely, the variable bound by it), because the former is c-commanded by the locative PP that dominates the latter.

(ii) A pronoun $\mathrm{P}$ may be linked to a variable $\mathrm{V}$ iff $\mathrm{V}$ almost c-commands $\mathrm{P}$. (A almost c-commands $\mathrm{B}={ }_{\text {def }} \mathrm{A}$ c-commands $\mathrm{B}$ or the projection $\mathrm{C}$ that dominates A c-commands B.)

(Hornstein (1995: 108)) 
(10) The Phase Impenetrability Condition

The domain of $\mathrm{H}$ is not accessible to operations outside HP; only $\mathrm{H}$ and its edge are accessible to such operations.

(Chomsky (2001: 13))

Another property of the sentence-initial locative PP that aligns it with a topic is that it cannot occur in ECM constructions, just like the topicalized element in (11).

(11) a. *John believes (for) to Mary, Sam to have given a book.

b. *John believes Sam to Mary, to have given a book.

(Nishihara (1999: 389))

(12) *I wouldn't expect behind the trees to stand a large building of some kind.

(Levine (1989: 1037))

Given the standard assumption that ECM constructions are TP, the ungrammaticality of (12) is accounted for because they do not provide a landing site for the movement of the locative PP, which is a topic and must move to SpecTopP under the present analysis.

In sum, this section has proposed a new syntactic structure of the unaccusative LIC in which the subject DP agrees in situ with $\mathrm{T}$ and the locative PP moves simultaneously to SpecTP and SpecTopP under independent probing by $\mathrm{T}$ and Top. This correctly captures, among other properties, the subjecthood and topichood of the locative PP, which have long resisted a principled explanation (see section 4 for a critical review of previous studies). ${ }^{9}$

9 Although motion verbs are usually classified as unergatives, the LIC based on them patterns with the unaccusative LIC: it need not have a heavy subject DP as in (ia), and it can be embedded under raising predicates as in (ib).

(i) a. Out of the barn ran a black horse.

b. Into every man's room seems to have intruded a burglar.

(Coopmans (1989: 732))

(Kitada (2011: 94))

It has been argued in a number of studies that motion verbs behave like unaccusatives when they are combined with a directional PP (cf. Coopmans (1989), Hoekstra and Mulder (1990)). Given their arguments, it is reasonable to assume with Culicover and Levine (2001) that the LIC based on motion verbs has the same syntactic structure as the unaccusative LIC, i.e. (4b) under the present analysis. 
3. The Unergative LIC

3.1. The Syntactic Structure of the Unergative LIC

This paper proposes the following syntactic structure of the unergative LIC, which is basically along the lines of Culicover and Levine (2001), adapted to the framework of the Minimalist Program.

(13) a. On the stage dances the girl who plays Joan of Arc in the school festival.

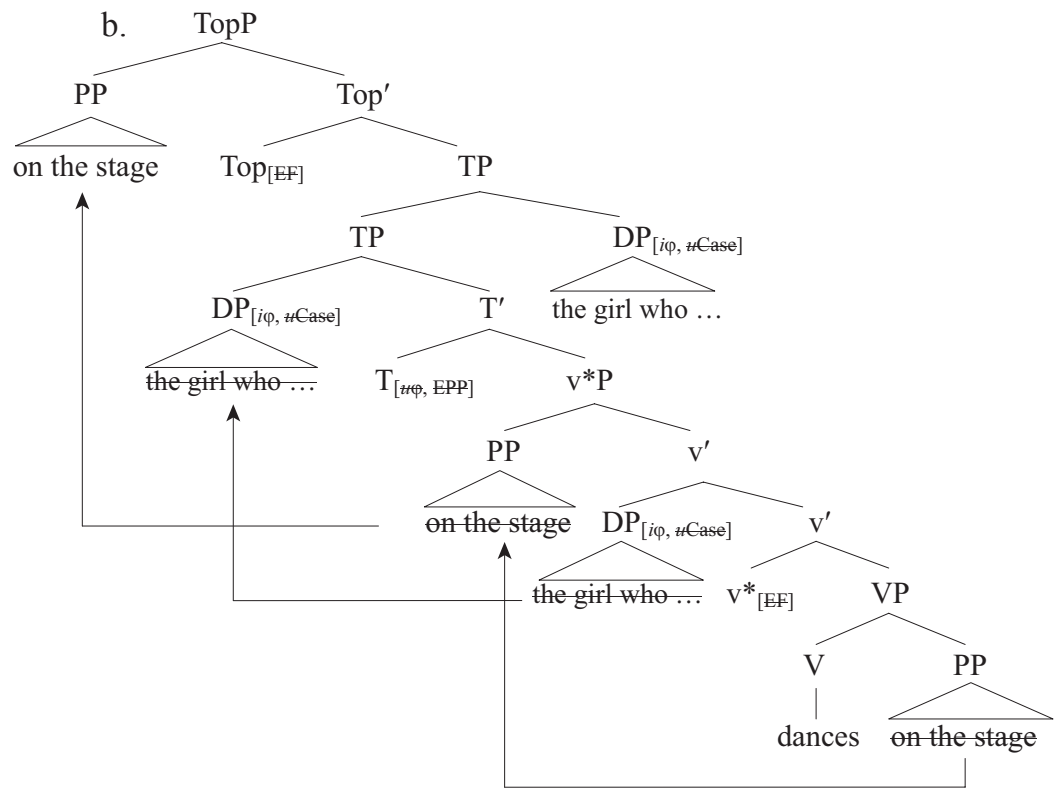

In (13), the subject DP is merged in Specv*P and the locative PP is merged in the complement position of $\mathrm{V}$, respectively. In the $\mathrm{V}^{*} \mathrm{P}$ phase, the edge feature on $\mathrm{V}^{*}$ probes and attracts the locative PP from the complement position of $\mathrm{V}$ to the outer Specv*P. In the TopP phase, the Agree feature on $\mathrm{T}$ probes and enters into an Agree relation with the subject DP in Specv*P, and the EPP-feature on $\mathrm{T}$ probes and attracts it from Specv*P to SpecTP, deleting the Agree feature on $\mathrm{T}$ and the Case feature on the subject DP which are both uninterpretable. Then, HNPS applies to the subject DP in SpecTP to adjoin it to the right of TP. ${ }^{10}$ In addition to these operations

${ }^{10}$ HNPS is an optional operation, so the non-inverted sentence in (i) is derived when HNPS does not apply to the subject DP in SpecTP.

(i) On the stage, [the girl who plays Joan of Arc in the school festival] dances. 
by $T$, the edge feature on Top probes and attracts the locative PP from the outer Specv*P to SpecTopP. Since all the uninterpretable features have now been deleted, the derivation converges. Then, only the highest copies of the subject DP and locative PP are overtly spelled out in the phonological component, yielding the surface form of (13a).

It should be noticed that the above structure is the only way to derive the unergative LIC, given that unergative sentences involve a $\mathrm{v}^{*} \mathrm{P}$ phase. Unlike the unaccusative LIC, the EPP-feature on T can only be satisfied by the subject DP in the unergative LIC; since the locative PP has moved to the outer Specv*P, which is an $\mathrm{A}^{\prime}$-position (which is a necessary step for topicalization in the next phase), it cannot move further to SpecTP to satisfy the EPP-feature on $\mathrm{T}$ without causing improper movement. ${ }^{11}$ Then, the subject DP must move rightward from SpecTP to yield the word order in which it follows the unergative verb. It is natural to assume that this rightward movement is HNPS, which is attested elsewhere in English.

The next section shows how the proposed analysis accounts for the major syntactic properties of the unergative LIC.

\subsection{Explaining the Properties of the Unergative LIC}

First, consider the properties of the postverbal subject DP. As mentioned above, Culicover and Levine (2001) point out that it must be relatively heavy in that it requires phonological stress or modification for the unergative LIC to be acceptable, as illustrated in (14). This fact is consistent with the present analysis, according to which the subject DP undergoes HNPS to adjoin to TP.

a. *In the room [тр [тр slept fitfully] Robin].

b. Well, in the classroom [тр [тр slept fitfully] ROBIN]!

c. In the room [тр [тр slept fitfully] the students in the class who had heard about the social psych experiment that we were about to perpetrate].

(cf. Culicover and Levine (2001: 293))

Moreover, it is observed from (15a) that the postverbal subject DP can control PRO in adjunct clauses in the unergative LIC.

11 This paper assumes with Chomsky (2008) that $\mathrm{A}^{\prime}$-movement is defined as an instance of movement triggered under probing by an edge feature. Therefore, the outer Specv*P is an $\mathrm{A}^{\prime}$-position; if it were an A-position, adjunct wh-phases, which are merged in an $\mathrm{A}^{\prime}$-position, could not move out of $\mathrm{v}^{*} \mathrm{P}$ via the outer Specv*P without causing improper movement. 
(15) a. At the super market _ worked, without $\mathrm{PRO}_{\mathrm{i}}$ being near anyone, [a woman wearing a green cap $]_{i}$.

b. ... [тр $\left[\operatorname{Tp}_{\mathrm{DP}} \mathrm{DP}_{\mathrm{i}}\left[\mathrm{v}^{* \mathrm{P}}\left[\mathrm{v}^{*} \mathrm{p} \ldots\right]\right.\right.$ without $\mathrm{PRO}_{\mathrm{i}}$ being $\left.\left.\left.\ldots\right]\right] \mathrm{DP}_{\mathrm{i}}\right]$ (DP: a woman wearing a green cap)

This is because the subject DP undergoes A-movement to SpecTP, from which it c-commands and hence controls PRO in the adjunct clause, as shown in (15b).

Next, consider the properties of the sentence-initial locative PP. Interestingly, it cannot undergo raising from infinitival complements, as illustrated in (16a), with its structure in (16b) under the present analysis. This is the property that differentiates the unergative LIC from the unaccusative LIC.

(16) a. *At the corner seemed to smoke [a man wearing a red headband and dark sunglass.

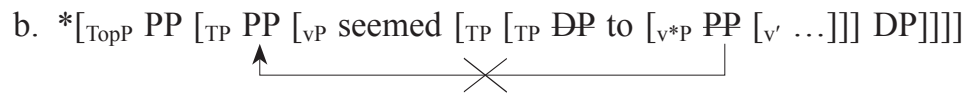

(PP: at the corner, DP: a man wearing a red headband and dark sunglass)

In the infinitival complement of (16b), the edge feature on $\mathrm{v}^{*}$ probes and attracts the locative PP to the outer Specv*P, while the EPP-feature on $\mathrm{T}$ probes and attracts the subject DP to SpecTP. Then, the subject DP undergoes HNPS to adjoin to the infinitival TP. If the locative PP underwent raising to the matrix SpecTP as in (16b), it would cause improper movement. Alternatively, if it were to move to SpecTopP without passing through SpecTP, the EPP-feature on T could not be satisfied. Thus, there is no way to yield the surface form of $(16 a) .^{12,13}$

12 Note that HNPS of the subject DP applies at the level of the infinitival TP in (16). Given that HNPS of a subject DP applies in the TP domain (cf. Culicover and Levine (2001)), the earliness principle of the kind proposed by Pesetsky (1991) will force the derivation in (16) and block the derivation which delays HNPS of the subject DP, where it undergoes HNPS at the level of the matrix TP after moving to the matrix SpecTP.

13 The presence of the weak crossover effect, which contrasts sharply with the case of the unaccusative LIC observed in footnote 8, also follows from the present analysis. In (i), since the locative PP only occupies SpecTopP as an $\mathrm{A}^{\prime}$-position, it cannot function as an appropriate antecedent of the bound variable pronoun contained within the subject DP.

(i) a.?*In every shop smoked its $_{i}$ owner who was wearing a red T-shirt.

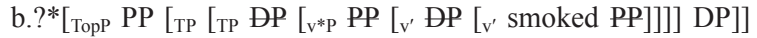

(PP: in every shop, DP: its owner who was wearing a red T-shirt) 
On the other hand, the sentence-initial locative PP has topichood in that it prevents $\mathrm{A}^{\prime}$-movement of the subject DP, exhibiting the topic island effect.
a. *Who do you think in the classroom slept?
b. *... think [ForceP who [Tоре in the classroom [те whe slept ...]]]?

Once the derivation reaches the TopP phase, the domain of Top, i.e. TP, is transferred and becomes inaccessible to operations outside TopP. Therefore, the edge feature on Force cannot attract the subject DP across the locative PP in SpecTopP without violating the PIC, as shown in (17b). Another indication of the topichood of the locative PP is that it cannot occur in ECM constructions, as shown in (18).

(18) *I expect at the corner to smoke [a man wearing a red headband and dark sunglass].

The ungrammaticality of (18) is due to the fact that the locative PP cannot find an appropriate landing site in ECM constructions which are TP.

In sum, this section has made a proposal about the syntactic structure of the unergative LIC, where the subject DP moves to SpecTP and then undergoes HNPS to adjoin to the right of TP, while the locative PP only moves to SpecTopP, but not to SpecTP. This correctly accounts for the major syntactic properties of the unergative LIC, especially, the heaviness of the subject DP and the lack of subjecthood of the locative PP, in which it diverges from the unaccusative LIC.

The next section overviews two recent studies on the LIC, pointing out their empirical insufficiencies.

\section{Previous Studies}

4.1. Mikami (2010)

Mikami (2010) proposes the following syntactic structure of the unaccusative LIC. 


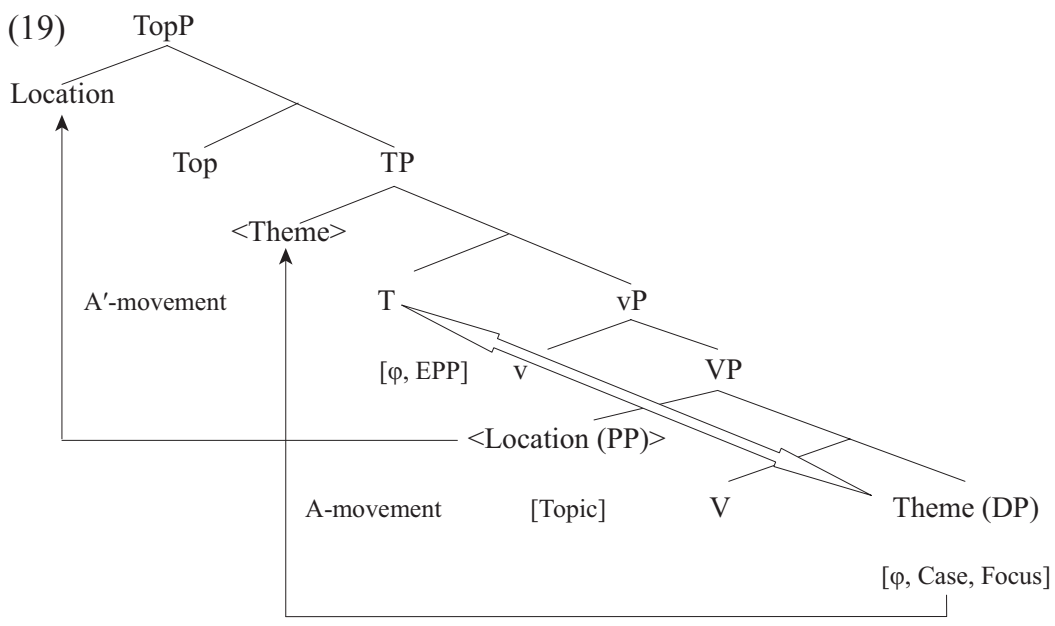

(Mikami (2010: 313))

The subject DP and locative PP are merged in the complement position of $\mathrm{V}$ and in SpecVP, respectively. As soon as $\mathrm{T}$ is merged, $\mathrm{T}$ probes and enters into an Agree relation with the subject DP, which in turn moves to SpecTP to satisfy the EPP-feature on T. When Top is merged, the locative PP, which is assigned [+Topic], moves to SpecTopP. After these operations, the structure is transferred to the phonological component, where the higher copy of the subject DP is deleted and its lower copy is pronounced with phonological stress and interpreted as a focused element. This results in the realization of the subject DP in the postverbal position.

Mikami assumes that the locative PP has only topichood, but he explains in terms of the pronunciation of the lower copy the following example of raising which other researchers regard as its subject property.

(20) a. [On that hill] appears to be located a cathedral. $\quad(=(8 \mathrm{a}))$

b. [TopP Loc ${ }_{\text {TтP }}<$ The $>\ldots[$ [тр $<$ The $>\ldots$ [vP $<$ Loc $>$ [V The $\left.\left.]\right]\right]$ (Loc: Location PP, The: Theme DP) (Mikami (2010: 317)) In (20b), the subject DP moves to the matrix SpecTP through the embedded SpecTP, while the locative PP moves to SpecTopP. In the phonological component, only the lowest copy of the subject DP is pronounced and the other copies are deleted, yielding the surface form of (20a) without recourse to A-movement of the locative PP.

Mikami's analysis, however, has some empirical problems. First, it cannot account for the fact in (21a) that the pronunciation of the subject DP in its base position is not allowed without the sentence-initial locative PP. It might be possible to assume that it depends on topicalization of the locative 
PP, but that is an ad hoc stipulation which needs an independent explanation. Given that topicalization (assignment of [+Topic] to the locative PP) is optional (see (21b)), the derivation of (21a) would converge, with the EPP-feature on $\mathrm{T}$ satisfied by the subject DP moving to SpecTP and its copy pronounced in its base position. In contrast, the analysis in this paper gives a simple explanation to the ungrammaticality of (21a): the EPPfeature on $\mathrm{T}$ would not be satisfied if the locative PP does not move to SpecTP, causing the derivation to crash as illustrated in (21c). (Given that an edge feature is optional, the absence of topicalization of the locative PP does not induce any kind of violation.)

(21) a. *Rolled \{the baby carriage down the hill / down the hill the baby carriage\}.

(cf. Coopmans (1989: 730))

b. The baby carriage rolled down the hill.

c. ${ }^{*}\left[{ }_{\text {Topp }}\left[\mathrm{Top}_{\mathrm{Top}} \mathrm{Top}_{([\mathrm{EF}])}\right]\left[{ }_{\mathrm{TP}}\left[\mathrm{T} \mathrm{T}_{[\mathrm{EPP}]}\right]\right.\right.$ [vP rolled ... down the hill]]]

Second, Mikami fails to capture the following sort of subjecthood of the locative PP, which illustrates the effect of the parallelism constraint on across-the-board rule application: a subject gap in one conjunct cannot occur with a nonsubject gap in the other conjunct (see Bresnan (1994) for the original formulation of this constraint). His analysis incorrectly predicts (22c) to be grammatical because the locative PP leaves a gap in the postverbal position in both conjuncts, just like (22b). On the other hand, the analysis in this paper correctly excludes this sentence as a violation of the parallelism constraint: the first conjunct has a gap in the postverbal position, while the second conjunct has a gap in the preverbal, subject position (as well as in the postverbal position).

(22) a. That's the old graveyard, in which [тр is buried a pirate] and [тр _ is likely to be buried a treasure]. (SUBJ-SUBJ)

b. That's the old graveyard, in which [тр workers are digging ___ ] and [тр a treasure is likely to be buried __ ].

(NONSUBJ-NONSUBJ)

c.?? That's the old graveyard, in which [тр workers are digging __ _ and [те _ is likely to be buried a treasure].

(NONSUBJ-SUBJ)

(cf. Bresnan (1994: 98))

\subsection{Kitada (2011)}

Kitada (2011) argues that the edge feature can be inherited from $\mathrm{C}$ to $\mathrm{T}$ when the Agree feature on $\mathrm{T}$ does not trigger A-movement of the agreeing DP. According to him, this is what happens in the derivation of the LIC. 
(23)

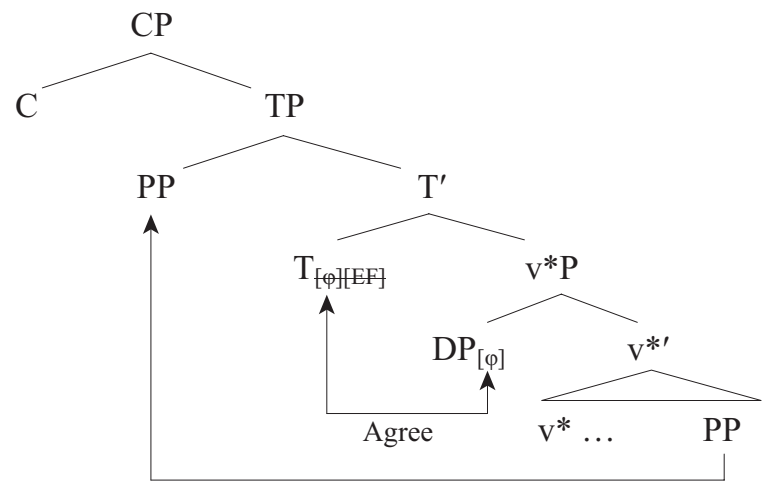

$\mathrm{A}^{\prime}$-movement by the checking of the EF

(cf. Kitada (2011: 93))

In (23), the edge feature, which is inherited from $\mathrm{C}$ to $\mathrm{T}$, triggers $\mathrm{A}^{\prime}$ movement of the locative PP to SpecTP. Thus, although the LIC has the locative PP in SpecTP, it has undergone $\mathrm{A}^{\prime}$-movement under probing by the edge feature, from which Kitada argues its dual properties as a subject and as a topic are derived. ${ }^{14}$ (Note that SpecTP is unambiguously an $\mathrm{A}^{\prime}-$ position in (23); Conceptual-Intentional interface conditions do not allow a position which is an A-position and $\mathrm{A}^{\prime}$-position simultaneously, as discussed in Kitada (2011)).

However, there remain some problems with Kitada's analysis. First, since he assumes that topicalization to the $\mathrm{CP}$ domain is not involved in the derivation of the LIC, it seems difficult to account for the fact that locative inversion patterns with topicalization in that it can occur in an assertive clause, but not in a non-assertive clause, as shown in (24) and (25). Assuming that TopP is projected only in an assertive clause, the contrast in (25) immediately follows from the present analysis in which the locative PP

14 Kitada cites the example in (i), which involves a motion verb and hence instantiates the unaccusative LIC (see footnote 9), arguing that the locative PP occupies an A'position and hence cannot function as an antecedent of the bound variable pronoun.

(i) *Into every man $_{i}$ 's room seems to $\mathrm{him}_{\mathrm{i}}$ to have intruded a burglar.

(Kitada (2011: 94))

However, the ungrammaticality of (i) cannot constitute evidence for the $\mathrm{A}^{\prime}$-status of the locative PP; it will be excluded (perhaps as a violation of principle B of the binding theory) on a par with examples like (ii), where the subject DP in SpecTP cannot be an antecedent of the bound variable pronoun in the complement position of $\mathrm{P}$.

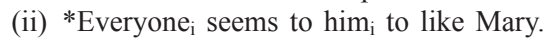

Therefore, the example in (i) is not problematic for the present analysis in which the locative PP undergoes A-movement to SpecTP. 
undergoes movement to SpecTopP.

(24) a. Bill says that such books he only reads at home.

b. *Bill asked if such books he only reads at home.

(Nishihara (1999: 389))

(25) a. John says that near his house lies a buried treasure.

b. *John asks if near his house lies a buried treasure.

(Nishihara (1999: 389))

Second, Kitada's analysis fails to accommodate the observation that the locative PP in the LIC can license negative polarity items, a property which it shares with a subject DP in (26a), but not with a topicalized PP in (26b).

(26) a. None of the students walked into any of the classrooms.

b. *Into none of the classrooms any of the students walked.

(Nishihara (1999: 389-390))

(27) a. In none of the corners stands any of the structures.

(Nishihara (1999: 390))

b. [торР PP [тр PP [vр stands any of the structures PP].

(PP: in none of the corners)

Assuming with Nishihara (1999) that negative polarity items are licensed by c-commanding affective elements in A-positions, Kitada's analysis, in which the locative PP occupies SpecTP as an A'-position, incorrectly predicts (27a) to be ungrammatical. ${ }^{15}$ In contrast, the analysis in this paper posits that the locative PP undergoes A-movement to SpecTP, which serves to license negative polarity items, as shown in (27b).

In sum, this section has overviewed Mikami (2010) and Kitada (2011), who assume the (non-parallel) movement of the locative PP to SpecTopP and SpecTP, respectively, and presented several facts which are difficult to account for under their analyses. In contrast, it has been shown that these facts are accounted for straightforwardly under the analysis in this paper, thus providing its advantage over the analyses by the two authors.

15 Kitada suggests that the locative PP can be merged in a higher position than the subject DP; if this is correct, the former would c-command the latter in their base positions, thereby accounting for the grammaticality of (27a). But this suggestion immediately turns out to be untenable: it cannot distinguish the grammatical (27a) from the ungrammatical (26b), because the hierarchical relation between the locative PP and the subject DP in their base positions should be the same in these two sentences. In contrast, the ungrammaticality of (26b) is immediately accounted for under the analysis in this paper: the negative polarity item in SpecTP cannot be licensed by the locative PP which occupies SpecTopP as an $\mathrm{A}^{\prime}$-position. 


\section{Concluding Remarks}

This paper has proposed the syntactic structures of the two types of LIC and tried to account for their major syntactic properties within the framework of the Minimalist Program. In the unaccusative LIC, while the subject DP agrees in situ with $\mathrm{T}$, the locative PP moves simultaneously to SpecTP and SpecTopP under independent probing by $\mathrm{T}$ and Top. In the unergative LIC, on the other hand, while the subject DP moves to SpecTP and then undergoes HNPS, the locative PP moves only to SpecTopP. These syntactic structures provide a basis for accounting for both the similarities and differences between the two types of LIC in a principled way, especially the dual properties of the locative PP in the unaccusative LIC and the lack of subjecthood of the locative PP in the unergative LIC.

\section{REFERENCES}

Bošković, Željko (1997) The Syntax of Nonfinite Complementation: An Economy Approach, MIT Press, Cambridge, MA.

Bresnan, Joan W. (1994) "Locative Inversion and the Architecture of Universal Grammar," Language 70, 72-137.

Chomsky, Noam (1995) The Minimalist Program, MIT Press, Cambridge, MA.

Chomsky, Noam (2000) "Minimalist Inquiries: The Framework," Step by Step: Essays on Minimalist Syntax in Honor of Howard Lansnik, ed. by Roger Martin, David Michaels and Juan Uriagereka, 89-155, MIT Press, Cambridge, MA.

Chomsky, Noam (2001) "Derivation by Phase," Ken Hale: A Life in Language, ed. by Michael Kenstowicz, 1-52, MIT Press, Cambridge, MA.

Chomsky, Noam (2008) "On Phases," Foundational Issues in Linguistic Theory, 133-166, MIT Press, Cambridge, MA.

Collins, Chris (1997) Local Economy, MIT Press, Cambridge, MA.

Coopmans, Peter (1989) "Where Stylistic and Syntactic Processes Meet: Locative Inversion in English," Language 65, 728-751.

Culicover, Peter W. and Robert D. Levine (2001) "Stylistic Inversion in English: A Reconsideration," Natural Language and Linguistic Theory 19, 283-310.

Diesing, Molly (1992) Indefinites, MIT Press, Cambridge, MA.

Doggett, Teal Bissell (2004) All Things Being Unequal: Locality in Movement, Doctoral dissertation, MIT.

Hale, Kenneth and Samuel J. Keyser (1993) "On Argument Structure and the Lexical Expression of Syntactic Relations," The View from Building 20: Essays in Linguistics in Honor of Sylvain Bromberger, ed. by Kenneth Hale and Samuel Jay Keyser, 53-109, MIT Press, Cambridge, MA.

Hoekstra, Teun and René Mulder (1990) "Unergatives as Copula Verbs: Locational 
and Existential Predication," The Linguistic Review 7, 1-79.

Hornstein, Norbert (1995) Logical Form: From GB to Minimalism, Blackwell, Oxford.

Hornstein, Norbert and Jairo Nunes (2002) "On Asymmetries between Parasitic Gap and Across-the-Board Constructions," Syntax 5, 26-54.

Kitada, Shin-ichi (2011) "C-to-T Inheritance of Edge Features," Studies in English Literature 52, 77-101.

Kuno, Susumu and Kenichi Takami (2007) Eigo no Kobun to Sono Imi: Seiseibunpo to Kinoteki Kobunron (English Constructions and Their Meaning: Generative Grammar and Functional Theory of the Constructions), Kaitakusha, Tokyo.

Lambrecht, Knud (1994) Information Structure and Sentence Form: Topic, Focus, and the Mental Representations of Discourse Referents, Cambridge University Press, Cambridge.

Larson, Richard K. (1988) "On the Double Object Construction," Linguistic Inquiry 19, 335-391.

Lasnik, Howard and Mamoru Saito (1992) Move $\alpha$ : Conditions on Its Application and Output, MIT Press, Cambridge, MA.

Levin, Beth and Malka Rappaport Hovav (1995) Unaccusativity: At the Syntax-Lexical Semantics Interface, MIT Press, Cambridge, MA.

Levine, Robert D. (1989) "On Focus Inversion: Syntactic Valence and the Role of a SUBCAT List,” Linguistics 27, 1013-1055.

Maeda, Masako (2012) "The Fine Structure of the vP Periphery and Heavy NP Shift/Locative Inversion," JELS 29, 267-273.

Mikami, Suguru (2010) "The Locative Inversion Construction in English: Topicalization and the Pronunciation of the Lower Copy," English Linguistics 27, 299-328.

Nishihara, Toshiaki (1999) "On Locative Inversion and There-Construction," English Linguistics 16, 381-404.

Nissenbaum, Jonathan W. (2000) Investigations of Covert Phrase Movement, Doctoral dissertation, MIT.

Partee, Barbara, H. (1991) "Topic, Focus, and Quantification," Proceedings of the 1st Semantics and Linguistic Theory Conference, 159-188.

Pesetsky, David (1991) "Zero Syntax: vol. 2: Infinitives," ms., MIT. <http://web.mit. edu/ linguistics/people/faculty/pesetsky/infins.pdf>

Postal, Paul M. (1977) “About a "Nonargument" for Raising," Linguistic Inquiry 8, $141-154$.

Radford, Andrew (2009) An Introduction to English Sentence Structure, Cambridge University Press, Cambridge.

Reinhart, Tanya (1983) Anaphora and Semantic Interpretation, Croom Helm, London.

Rizzi, Luigi (1997) "The Fine Structure of the Left Periphery," Elements of Grammar: Handbook of Generative Syntax, ed. by Liliane Haegeman, 281-337, Kluwer, Dordrecht.

Safir, Ken (2004) The Syntax of (In)dependence, MIT Press, Cambridge, MA. 
Williams, Edwin S. (1980) "Predication," Linguistic Inquiry 11, 203-238.

[received March 29, 2013, revised and accepted July 19, 2013]

Department of English Linguistics

Graduate School of Letters

Nagoya University

Furo-cho, Chikusa-ku, Nagoya-shi

Aichi 464-8601

e-mail: koike.kouji@b.mbox.nagoya-u.ac.jp 